\section{THE COMMON FROG*}

XII.

SO much for the circulation of the frog in its adult condition. Its larval, or tadpole stage, presents us with a series of changes which, though more familiar, are not less wonderful.

In the first place, however, it may be well to describe shortly the condition of the circulation in fishes, where the purification of the blood is effected, not by means of the exposure of the blood to the action of air taken into respiratory cavities of the body, but by its subjection in little plates of membrane, the gills, to the influence of air mechanically mixed up with and dissolved in the water in which those gills are bathed.

In fishes, moreover, unlike all air-breathing animals, none of the oxygenated blood is returned to the heart for propulsion, but is collected directly into the great dorsal aorta, whence it is distributed to the whole body, only being returned to the heart after such distribution, so that venous blood alone enters that organ.

This venous blood is sent out from the heart through a bulbous aorta, whence arise on each side a series of arteries which ascend the branchial arches, one on the outer side of each such arch, decreasing in size as it ascends.

Each branchial artery gives off small gill arteries, which run along one edge of each little membranous leaflet or gill, and supply it with minute branches ending in capillaries, in which the blood is purified. There the purified blood is taken up by minute veins which open into gill veins, one of which runs along the opposite edge of each gill to that occupied by the gill artery.

The gill veins pour their contents into branchial veins, one of which ascends the outer side of each branchial arch, increasing in size as it ascends. The branchial veins open into the great dorsal aorta, whence the blood is distributed over the body. Generally the branchial arteries are only connected with the branchial veins by the intervention of the capillary vessels of the gills. Sometimes, however (as e.g. in the mud-fish, Lepidosiren), the branchial veins are directly continuous with the branchial arteries.

In the tadpole, while the gills remain fully developed, a condition exists quite similar to that of fishes. Minute vessels, however, directly connect together, at the root of each gill, the branchial artery and branchial vein of each gill. Such a connecting vessel is termed a ductus botalli.

A minute vessel given off from the third branchial artery, is the incipient pulmonary artery.

As development proceeds, as the gills diminish by absorption, and as their respective arteries and veins decrease in size and importance, each ductus botalli increases until at last we have established the six great continuous vessels of the adult frog.

We have, then, in the life-history of the frog, a complete transition from the condition of the fish to that of a true air-breathing vertebrate, as regards its circulation. The various conditions herein referred to have, however, an important bearing on the question of the first origin of such structure.

All higher animals, even the very highest, have the great arteries, whon they first appear, arranged substantially as in fishes.

From the common aortic bulb five vessels ascend each side of the neck, and more or fewer of these arteries abound in different classes, the permanent adult condition being arrived at by this circuitous route.

This argument has commonly been adduced as an argument in favour of the descent of air-breathing animals from more ancient gill-bearing forms, and it is not with. out weight.

\footnotetext{
Continued from p. $3^{60}$
}

Nevertheless it must be borne in mind that the primitive condition in Fishes is that of direct continuity between the branchial arteries and veins such as we have seen exists permanently in Lepidosiren. It is only as development proceeds that each primitive continuous arch

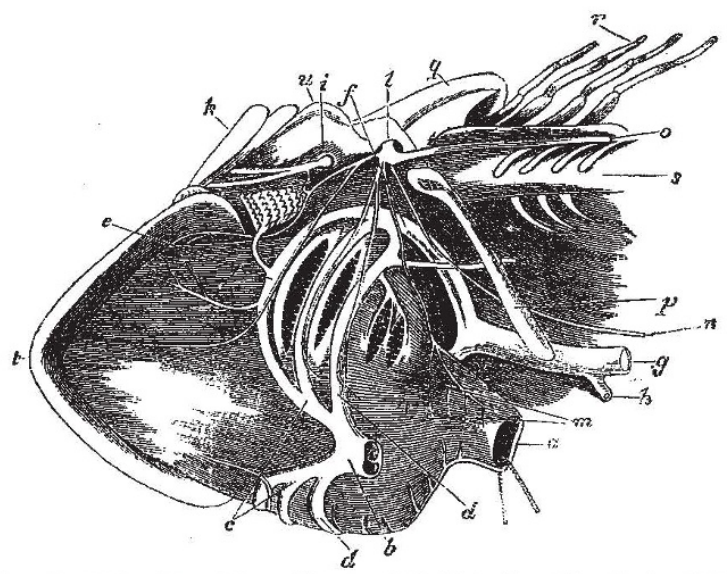

FIG. 78.-Infero-lateral view of Head and Aortic Arches of Lepidosiren (after Hyrtl). $a$, csophagus; $b$, anterior end of bulbus aortæ; $c$, common roots of the first aortic arches; $d$, third aortic arch; $e$, first aortic arch roots of the first aortic arches; $d$, third aortic arch; $e$, first aortic arch ; $f$, dorsal union of the first three aortic arches $; g$, aorta; $h$, coliac artery; , exit of the fifth nerve ; $k$, part of operculum;, , exit of the nervus vagus from the skull; $n t$, branches to csophagus; $n$, nerve going to the rectus abdominis ; $o$, nervus lateralis ; $p$, first and hypertrophied rib ; $q$, posterior part of the skull ; $r$, segu

becomes broken up into an artery and a vein connected by a net-work of capillaries.

Now we can understand the series of unbroken arches in higher animals as the relics of ancestral vessels which divided for gill circulation and were therefore once of extreme functional importance and utility. But how can we understand the primitive unbroken series of arches in Fishes? Their utility was yet to come !

The frog when adult has, besides its skin, no breathing organs but the lungs. As has been said before, other members of the Frog's class retain gills and aquatic respiration during the whole of life, as for example Meno. branchus.

Every one kind, however, whether provided permanently with gills or not, develops lungs, and it might easily be imagined that similarly every gilled-creature which has lungs is also a Batrachian.

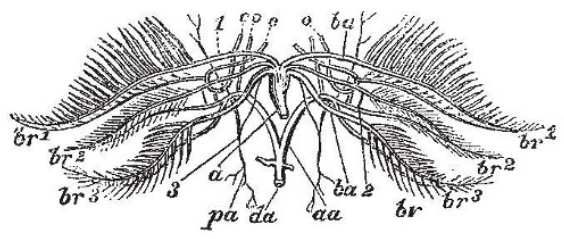

FIG. 79.-The Circulation of a Tadpole in its primitive stage, when nearly all the blood is distributed to the gills; the pulmonary arteries being quite rudimentary, and the to the gils, the pulmonary arteries being quite rudimentary, and the vessel (or ductus botalli) connecting together the branchial artery and vein at the root of each gill being minute. $a$, bulbus aorta; $b$, branchial arteries; $b r^{1}, b r^{2}, b r 3$, the three gills (or branchiz of each side); $b v$, the branchial veins which bring back the blood from the gills - the hindermost pair of branchial veins on each side unite to form an aortic arch $(a a)$, which again unites with its fellow of the opposite side to form $d a$, the descending (or dorsal) aorta. The branchial veins of the foremost gills give rise to the carotid arteries, $c c$. $o$, artery going to the orbit ; $p a$, pulmonary artery ; $1,2,3$, anastomosing branches connecting together the adjacent branchial arteries and veins.

This, however, would be a mistake.

The Mud-fish or Lepidosiren, already referred to more than once, is furnished with both gills and lungs throughout the whole of life. On this account it has been reckoned by some naturalists to be a Fish and not a Batrachian. Its fish-nature, however, has now been tho- 
roughly established, and thus the probability of the existence of lungs within the class of fishes is also established.

But what is a lung?

A lung is a sac-like structure capable of being distended with air, supplied with venous blood direct from the heart and sending arterial blood directly to it. Generally the whole of the blood from the lungs goes back to the heart directly, but in one Batrachian-the celebrated Proteusa portion of the blood from the lungs finds its way not

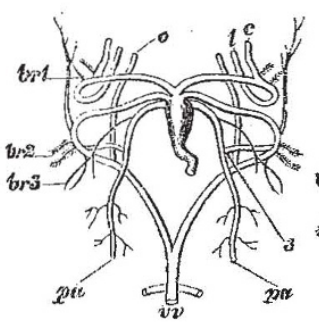

FIG. 80.

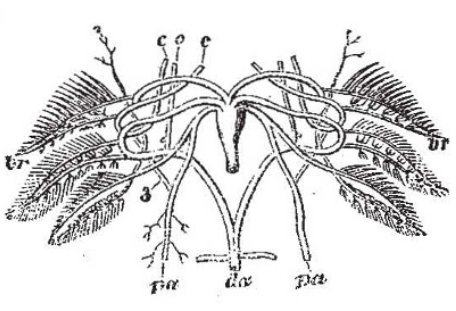

Fig. $8 \mathrm{r}$.
Fig. 8o.--The Circulation in a Tadpole at a more advanced stage, when the gills have begun to be absorbed, the pulmonary arteries to increase, as also the connecting branches (at the root of the gills) between the branchial arteries and branchial veins.

FIG. 81--The Circulation in a young Frog. Here the gills have been absorbed, and the blood passes directly from the heart to the head, the dorsal aorta, the lungs, and the skin,

in to the heart but into vessels of the general circulation. When there is an air-sac which does not both receive blood directly from and return it directly to the hearti.e. when there is no true pulnonary circulation-such an air-sac (whether single or double) is termed a swimbladder and a structure of the kind is found in very many fishes. The swim-bladder of ordinary fishes neither receives blood directly from the heart by an artery like the pulmonary artery of higher animals, nor does it return blood directly to the heart.

The transition, however, from a lung to a swim-bladder is a graduated one. We have just seen that in Protents,

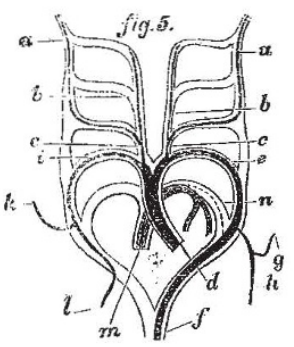

FIG. 8 2.

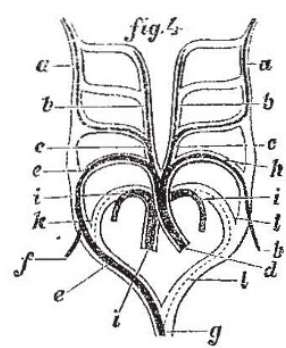

Fig. 83 .
Fig. 82,-Diagram representing the main arteries of a Bird (fowl) with the changes induced on the primitive condition (after H. Rathke). $a, a$, changes induced on the external carotids ; $c, c$, common carotids; $d$, root internal carotids, $f$, extre right): $e$, arch of the same $; f$, right subclavian of main aortic arch (here right); $e$, arch of the same ; , right subclavian (which arises from the anastomosis of the first two right primitive aortic arches) $; g$, commencement of the descend $i$, left, rudiments of the primi$i, i, i$, pulmonary

FIG. 83.-Diagram representing the main arteries of a Mammal with the changes induced in the primitive condition (after H. Rathke). $a, b, c$, carotids, as before, $d$, root of main aortic arch (here left), $e$, arch o the same; $f$, commencement of descending aorta; $g$, left vertebra artery, $h$, left subclavian $i$, right subclavian; $k$, right vertebral arters, $l$, continuation or right subch

though blood is returned from the lungs direct to the heart, yet that not all the blood is so returned. On the other hand in another animal, Ceratodus, though blood is not brought to its air-sac directly (which is therefore a swim-bladder and not a lung), yet for all that blood is sent from it direct to the heart.

Ceratodus (or as it is locally called "flat-head") is a fish of Queensland, closely allied to Lepicosiren, and is a very noteworthy animal apart from and in addition to its peculiarly transitional structure as regards its air-sac.

It is, indeed, the last of an ancient race, a species of the same genus (known almost exclusively by its teeth) being found fossil in strata of oolitic and triassic date. It was discovered by the Hon. W. Foster, M.C.A. Mr. Gerard Krefft, F.L.S., Curator and Secretary of the Sydney Museum, first described and figured the animal in I $870, *$ and at once correctly referred it to the genus Ceratodus, which up to that time was supposed to be entirely extinct. Its further determination was effected by Dr. Günther. $\dagger \mathrm{He}$ has conclusively shown that Ceratodus and Lepidosiren are closely allied, and thus finally brought the latter definitively within the class of Fishes, for that Ceratodus is a fish no one questions. It is an animal, however, of somewhat amphibious habits, as at night it leaves the brackish streams it inhabits, and wanders amongst the reeds and rushes of the adjacent flats. Vegetable substances constitute its principal food.

Ceratodus and Lepidosiren together afford the most remarkable evidence of the persistence of the same type of structure in the Vertebrate sub-kingdom. The group to which they both belong reaches back into the very earliest epoch, which has yet afforded us any evidence whatever of the existence of fishes; while the genus Ceratodus seems to have persisted unchanged from the period of the deposition of the triassic strata.

\section{Summary.}

Taking a rapid retrospect of the course we have pur sued, we find that in seeking to decide as to "What is a Frog?" our inquiry into its absolute structure has made known to us an animal of peculiarly specialised and perfect organisation. This has been shown to us pre-eminently by the study of its skeleton. We have especially noted its skull, its wonderfully short vertebral column, its utterly anomalous pelvis, and its scarcely less anomalous foot. The flesh which clothes that skeleton has been seen to exhibit distinct muscles wonderfully like our own, those of the foot, indeed, exceeding ours in number, and being a very marvel of complexity. We have met with a nervous system ministered to by delicate organs of sense, and noted for the ready response to stimuli, made by even separated parts of it as evidenced by strikingly coordinated complex movements. We have found the circulation to be carried on by a heart which, at first sight, seems too structurally imperfect to distribute the venous and arterial blood in their respectively appropriate channels. Nevertheless, further examination has shown us that this heart is provided with a special arrangement of parts so delicately co-adjusted as to be able to act thus as efficaciously as does the heart of animals much higher in the scale. Respiration, too, we have seen provided for partly by an effective throat air-pump, partly by a peculiar activity of the cutaneous structures.

We have, moreover, found that this complex adult condition is arrived at by means of a rapid metamorphosis from an immature condition wonderfully different, indeed, but no less perfectly adapted to the life conditions of the tadpole state.

It remains now "to sum up the results" of our investigations through "a series of wider and wider comparisons" to answer, finally, as far as may be, the initial question of this little treatise.

We have, in the first place, seen that the frog belongs to an order far more distinct from cognate ordinal groups than is man's order from other orders of his class mammalia. We have also seen that the frog belongs to an order which is singularly homogeneous, and yet that the class which includes it is remarkably heterogeneous.

Again, we have found that the subordinate groups of the frog's order, families and genera, have very definite

* See "Proc. Zool," Soc 187o, p. 22.

+ Sec "Phil. Trans." 877 , p. 5 ז 1 ; Plates xxx. to xlii. 
relations to space, and that the order; as a whole, is, as far as yet known, remarkably restricted as regards geological time.

The comparisons instituted in our survey of the frog's anatomy will enable us now to sum up resemblances; first, as regards the orders of its class, and secondly, as regards the class itself.

x. Its own order, Anoura, has been seen to present singular resemblances to the Chelonia amongst reptiles. Such are the bony plates of the back of some forms, the bony covering of the temporal fossa in others, the mode of inspiration in the adult, the armature of the jaws in the young. On the other hand, the peculiar elongated tarsus has reminded us of certain mammals, and the median Eustachian opening of Pipa and Dactylethra has suggested an affinity to crocodiles and birds. It has been plain, however, that these several likenesses, however singular and striking, are not evidences of genetic affinity.

2. The order Urodela may well recall to mind the Lacertilia amongst reptiles, with which animais the Urodela were actually classed by Linneus. Moreover in both groups we find a series of different species, longer and longer in body and shorter and shorter in limb. We have also seen that in both these groups an analogous complication obtains in the muscles of the legs.

3. The order Uphiomorpha, as has been before observed, present a general resemblance to serpents, and a special resemblance to certain short-tailed ones; though it is rather to the Amphisbenian Saurians that they may most advantageously be compared. Here, again, however, we meet with the resemblances which, though striking, do not allow themselves to be interpreted as indices of any special relationship by descent.

4. The order Labyrinthodonta recalls to mind, as has been said earlier, the Crocodilia amongst reptiles, of which they may be deemed as the prophetic precursors, so to speak, though certainly not the direct ancestors.

Thus the class Batrachia, as a whole, presents a very interesting analogy and parallelism with the class Reptilic. It is a parallelism, moreover, which reminds us of that which exists between the various orders of Placental mammals and the great subdivisions of the pouched or Marsupial order of mammals. Wehave carnivorous, insectivorous, arboreal, aquatic, herbivorous, marsupial beasts, as we have carnivorous, insectivorous, arboreal, aquatic and herbivorous placental beasts. The harmonious variations of the placental and marsupial groups thus present us with excellent instances of affinities independently evolved and not due to hereditary influence.

In a similar way it seems probable that the subdivisions (orders) of the class Batrachia, mimic, as it were quite independently, the subdivisions (orders) of the class Reptilia.

The Frogs' class, as a whole, shows as many striking affinities to some or other fishes. It does so in the possession of gills and of a branchial apparatus ciming one time of life at the least; a large parasphenoid in the skull; the often persistently unsegmented terminal part of the notochord; the single ventricular cavity of the heart; the presence of a bulbus aorta; the development of a nervus lateralis; the communication between the urinary canal and the oviduct, and certain other characters of less importance.

The class Batrachia agrees both with fishes and reptiles in having the blood cold, more than one aortic arch, and (except in crocodiles) in not having the distinct ventricles.

The class agrees with fishes, reptiles, and birds, in having no complete diaphragm, and no corpus callosum* in the brain, and no single aorta arching over the left bronchus.

We have now arrived at the end of those considerations seemingly best suited to enable us to answer the initial question, "What is a Frog?" The requisite definition might, of course, have been given much earlier, but these inquiries have seemed necessary to enable the reader to

* As to this structure see Lesson in "Elementary Anatomy," pp. $367,375$. understand the technical terms of such definition-to give them, in his eyes, a real meaning.

The Frog is a tailless, lung-breathing, branchiate vertebrate, with four limbs typically differentiated, undergoing a complete metamorphosis, and provided with teeth along margins of the upper jaw.

The course of our inquiry into the nature and affinities of the Frog has not alone served to answer the question with which this memoir opened. Incidental bearings upon deep biological problems have come before us more than once in its course, nor have all the conclusions which seem to have forced themselves upon us been totally negative.

Thus we have met with several instances of the independent origin of remarkably similar structures, such as a shielded temporal fossa and elongated tarsus, which, together with structures like the tooth of the Labyrinthodon, seem to be characters for the existence of which neither the destructive agencies of nature acting on minute oscillations of structure, nor any sexual phenomena, will account.

Again, in the life-history of the Frog, considered even purely by itself, we find a remarkable example of spontaneous transformations due to innate powers and tendencies.

When, however, this process is considered in the light derived from the curious phenomena of transformation so enigmatically presented to us by the axolotl, we have very strongly brought before us the powerful action of internal tendencies lying dormant and latent till made manifest, through the advent of conditions so obscure that as yet they have evaded the most careful and anxious scrutiny of practised adepts.

It would seem to be a negligence not here to point out, that if new forms of life-new species--arise from time to time through congenital variation, not a few of the facts herein quoted point to the probability that such forms have arisen through the evolutions of implanted potentialities definite in nature, in other words, by "specific genesis."

Again, a general survey of the different kinds of relations which the Frog has brough: before us, is well calculated to impress us with the overwhelming richness and fulness of nature.

Although, from our ignorance, the natural history of many other animals well known to us may appear less replete with interest than that of the common Frog may now be, yet it cannot be doubted but that the progress of science is capable of revealing to us facts as full of instruction and of as profound a significance in the life history of almost any kind of animal whatever.

Ever fresh, ever fertile, natural history offers to our faculties a pursuit practically inexhaustible. We are not, indeed, denied the gratification of successfully exploring and satisfactorily explaining mystery after mystery, but each secret wrested by our efforts brings before us other ever new enigmas, so that though refreshed by success we need never be wearied by monotony. While we need not regard any problem as absolutely hopeless, no dread of coming to the end of our inquiries need ever chill the warmth of our zeal in the scientific cause. Some may consider such reflections justified by the phenomena presented to them by the natural history of the Common Frog.

\section{St. George Mivart}

\section{THE HABITS OF BEES AND WASPS *}

SIR JOHN LUBBOCK, in a paper on the Social Hymenoptera (Bees, Wasps, and Ants), especially with reference to their habits, senses, and power of communication with one another, pointed out with regard to the latter, that the observations on record scarcely justify the conclusions which have been drawn from them.

* Being the substance of a paper by Sir John Lubbock, Part.. K.R.S. read before the Linnean Society on the 19 th March, 1874 . 